\title{
Analysis of MRI by fractals for prediction of sensory attributes: A case study in loin
}

Caballero, Daniel; Antequera, Teresa; Caro, Andrés; Amigo, José Manuel; Ersbøll, Bjarne Kjær; Dahl, Anders Bjorholm; Pérez-Palacios, Trinidad

Published in:

Journal of Food Engineering

Link to article, DOI:

10.1016/j.jfoodeng.2018.02.005

Publication date:

2018

Document Version

Peer reviewed version

Link back to DTU Orbit

Citation (APA):

Caballero, D., Antequera, T., Caro, A., Amigo, J. M., Ersbøll, B. K., Dahl, A. B., \& Pérez-Palacios, T. (2018). Analysis of MRI by fractals for prediction of sensory attributes: A case study in loin. Journal of Food Engineering, 227, 1-10. https://doi.org/10.1016/j.jfoodeng.2018.02.005

\section{General rights}

Copyright and moral rights for the publications made accessible in the public portal are retained by the authors and/or other copyright owners and it is a condition of accessing publications that users recognise and abide by the legal requirements associated with these rights.

- Users may download and print one copy of any publication from the public portal for the purpose of private study or research.

- You may not further distribute the material or use it for any profit-making activity or commercial gain

- You may freely distribute the URL identifying the publication in the public portal 


\title{
Analysis of MRI by fractals for prediction of sensory attributes: A case study in loin
}

\author{
Daniel Caballero ${ }^{\mathrm{a},{ }^{*},}$, Teresa Antequera ${ }^{\mathrm{a}}$, Andrés Caro ${ }^{\mathrm{b}}$, José Manuel Amigo ${ }^{\mathrm{c}}$, \\ Bjarne K. Ersbøll ${ }^{\text {d }}$, Anders B. Dahl ${ }^{\mathrm{e}}$, Trinidad Pérez-Palacios ${ }^{\mathrm{a}}$ \\ ${ }^{a}$ Food Technology Department, Research Institute of Meat and Meat Product (IProCar), University of Extremadura, Avda. de Las Ciencias S/N, ES-10003 \\ Cáceres, Spain \\ b Computer Science Department, Research Institute of Meat and Meat Product (IProCar), University of Extremadura, Avda. De Las Ciencias S/N, ES-10003 \\ Cáceres, Spain \\ ${ }^{c}$ Department of Food Science, Quality and Technology, Faculty of Life Science, University of Copenhagen, Rolighedsvej 30, DK-1958, Frediksberg C, Denmark \\ d Department of Informatics and Mathematical Modeling, Technical University of Denmark, Richard Petersen Plads, Building 324, DK-2800, Kongens Lyngby, \\ Denmark \\ e Department of Applied Mathematics and Computer Science, Technical University of Denmark, Richard Petersen Plads, Building 324, DK-2800, Kongens \\ Lyngby, Denmark
}

\section{A R T I C L E I N F O}

\section{Article history:}

Available online 7 February 2018

\section{Keywords:}

Fractals

MRI analysis

Data mining

Prediction

sensory traits

Meat

\begin{abstract}
A B S T R A C T
This study investigates the use of fractal algorithms to analyse MRI of meat products, specifically loin, in order to determine sensory parameters of loin. For that, the capability of different fractal algorithms was evaluated (Classical Fractal Algorithm, CFA; Fractal Texture Algorithm, FTA and One Point Fractal Texture Algorithm, OPFTA). Moreover, the influence of the acquisition sequence of MRI (Gradient echo, GE; Spin Echo, SE and Turbo 3D, T3D) and the predictive technique of data mining (Isotonic regression, IR and Multiple Linear regression, MLR) on the accuracy of the prediction was analysed. Results on this study firstly demonstrate the capability of fractal algorithms to analyse MRI from meat product. Different combinations of the analysed techniques can be applied for predicting most sensory attributes of loins adequately $(R>0.5)$. However, the combination of SE, OPFTA and MLR offered the most appropriate results. Thus, it could be proposed as an alternative to the traditional food technology methods.
\end{abstract}

(C) 2018 Elsevier Ltd. All rights reserved.

\section{Introduction}

Sensory analyses are carried out to measure the sensory quality of meat and meat products, being the quantitative-descriptive

Abbreviations: MRI, Magnetic resonance imaging; KDD, Knowledge discovery in databases; GE, Gradient Echo; SE, Spin Echo; T3D, Turbo 3D; RF, Radiofrequency; S/ N, Signal to noise; FOV, Field of view; TE, Echo time; TR, Repetition time; CFA Classical fractal algorithm; FTA, Fractal Texture Algorithm; UNI, Uniformity; ENT, Entropy; COR, Correlation; IDM, Inverse difference Moment; INE, Inertia; CON, Contrast; EMP, Emphasis; JC, Jorna's correlation; CS, Cluster shade; CP, Cluster prominence; OPFTA, One Point of Fractal Texture algorithm; ROI, Region of interest; HOM, Homogeneity; EFI, Efficiency; MLR, Multiple linear regression; IR, Isotonic regression; R, Correlation coefficient; MAE, Mean absolute error; PCA, Principal component analysis.

* Corresponding author.

E-mail addresses: dcaballero@unex.es (D. Caballero), tantero@unex.es (T. Antequera), andresc@unex.es (A. Caro), jmar@food.ku.dk (J.M. Amigo), bker@ dtu.dk (B.K. Ersbøll), abda@dtu.dk (A.B. Dahl), triny@unex.es (T. Pérez-Palacios). analyses the most widely used (Andrés et al., 2004; Ruiz et al., 1998). Data obtained by means of sensory analysis are as reliable as those from physical-chemical determinations (García and Carrapiso, 2001). These techniques measure the characteristics that influence consumers' acceptance, such as appearance, texture, odour, taste and flavour. Sensory analyses are tedious, time consuming and require the destruction of the pieces and a trained panel. In addition, in the case of meat products, they are carried out at the end of their processing, when there is no possibility of modifications to improve some sensory traits. In the last years, the evaluation of the meat and meat products by using non-destructive methods have given a great growth (Antequera et al., 2007; Collell et al., 2011; Fantazzini et al., 2009; Manzoco et al., 2013; PérezPalacios et al., 2014).

In this sense Magnetic Resonance Imaging (MRI) and computer vision techniques have been proposed as an alternative or complementary technique to traditional methods, since they are nondestructive, non-invasive, non-intrusive, non-radiant ionization 
and innocuous. In fact, several works have been carried out to determine quality attributes of hams (Antequera et al., 2007; Bajd et al., 2016; Caballero et al., 2016a, 2016b; Fantazzini et al., 2009; Manzoco et al., 2013; Pérez-Palacios et al., 2010, 2011; 2014) and loins (Antequera et al., 2003; Caballero et al., 2017a; Cernadas et al., 2001, 2005; Pérez-Palacios et al., 2015; 2017a) by using MRI. High field MRI scanners are frequently used in these researches, which implies high quality images but they are so expensive. In this sense, low field scanners that are cheaper could also be used for food analysis. The problem of this type of scanners is its low signal to noise ratio, being necessary the selection of an adequate sequence acquisition (Perez-Palacios et al., 2017a).

Most of these studies have used computational texture feature algorithms for analysing MRI. These algorithms integrate matrices based on second-order statistics in order to produce different computational texture features (Antequera et al., 2003; Cernadas et al., 2005). Pérez-Palacios et al. (2010, 2011) have found a relationship between computational texture features and some physico-chemical components and sensory attributes of Iberian hams.

In recent years, there is a growing interest in the use of fractal image analysis techniques instead of classical texture analysis methods. This is mainly because the image texture seeks to compress image information while the use of fractals allows the identification of recurring patterns, removing the possibility of image compression. The fractal concept studies the degree of symmetry or self-similarity found in a structure at all scales (Hibbert, 1991; Mandelbrot, 1982; Tominaga and Fujiwara, 1997; Sun et al., 2014). The most widely used algorithm is the classical fractal algorithm (CFA) (Mandelbrot, 1982), which is an implementation of Minkowski-Bouligand algorithm. CFA has been applied to characterize the microstructure of fruits and vegetables (Cárdenas-Pérez et al., 2016; Quevedo et al., 2016; Zhang et al., 2014), fish (Manera et al., 2016; Perisho et al., 2016), meat (Quevedo et al., 2013; Zapotoczny et al., 2016). However, only two studies about prediction of quality parameters of food have been found. Tsuta et al. (2002) applied them to predict the sugar content of melons and Polder et al. (2004) measured the chlorophyll of tomato by applying of fractals. Other fractal algorithms have been recently developed, fractal texture algorithm (FTA) (Caballero et al., 2017b) and one point of fractal curve texture algorithm (OPFTA) (Caballero et al., 2017c). Up to now, Caballero et al. (2017b) have applied FTA to analyse MRI from meat products in order to determine some quality characteristics non-destructively, whereas the use OPFTA in food have not been studied yet.

Data obtained from MRI analysis have been normally processed by applying usual statistical tools, such as Pearson's correlation coefficients or principal components analysis (Perez-Palacios et al., 2010). The integration of heterogeneous information with computer vision data and the analysis of this new data set by data management and database applications would be innovative and could give accurate results, playing an increasing role in furthering food research (Cortez et al., 2009; Holmes et al., 2012).

Currently, there is a growing interest in these techniques, mainly due to the decreasing cost of large storage devices and the development of robust and efficient algorithms to process these data sets (Mitchell, 1999). They are focused on extracting information from large data sets, grouped in what is known as Knowledge Discovery in Databases (KDD). Data mining is one of the data analysis stage in the KDD process, as a non-trivial process of finding knowledge and potentially useful information from data stored in repositories (Fayyad et al., 1996). It extracts hidden information by automatic or semi-automatic analysis, finding interesting unknown patterns (Sayad, 2011). There are some examples of data mining applied in quality traits of different meats (Cortez et al., 2006; Dissing et al.,
2013; Song et al., 2002), and determining some quality parameters of Iberian meat products (Caballero et al., 2016a, 2016b; 2017a; Pérez-Palacios et al., 2014, 2017a).

Combining image acquisition, image analysis and data analysis, the main objective of this study was to evaluate the capability of different fractal algorithms to analyse MRI of loins in order to predict sensory attributes of this product. In addition, the prediction accuracy of combinations of different sequence acquisitions of MRI, fractal algorithms to analyse MRI and predictive techniques of data mining were analysed.

\section{Material and methods}

\subsection{Experimental design}

Fig. 1 shows the experimental design of this study. Ten fresh loins were acquired from Montesano (Jerez de los Caballeros, Badajoz, Spain). Firstly, fresh loins were scanned by MRI. When they were processed, according to the traditional curing process following the procedure described by Pérez-Palacios et al. (2017a), MRI images were also retrieved for the dry-cured loins. All these MRI images were gathered in a MRI database. These images were acquired by using three different acquisition sequences (GE, SE and T3D), described in Section 2.3 (MRI acquisition). The obtained images from the database (from fresh and dry-cured loins) were analysed using three computer vision methods based on fractals (CFA, FTA and OPFTA). These methods are based on searching repeated patterns at different sizes. Numerical information from the images were gathered in a database (Computer vision data). Details about these algorithms could be found in Section 2.4 (Computer vision techniques). Besides, a quantitative-descriptive sensory analysis was carried out in dry-cured loins (Section 2.2. Sensory analysis). Average scores from eleven sensory traits for every dry-cured loin were stored in a database (Sensory data). Then, from these two databases (Sensory data and Computer Vision data) two data selection were performed, one of them from computer vision data of fresh loins and sensory data of dry-cured loins, and the other, with data from computer vision and sensory data of dry-cured loins. Finally, data mining techniques (Section 2.5. Prediction techniques) were applied on these databases for predicting sensory attributes of dry-cured loins as a function of fractals features from MRI of fresh and dry-cured loins $\left(P_{1}=a_{1} x+b_{1} y+c_{1} z\right.$, where $P_{1}$ is a sensory trait of dry-cured loin, $x, y$ and $z$ are fractal features and $a_{1}, b_{1}$ and $c_{1}$ are the weight for each fractal features). Specifically, MLR as lineal and IR as non-lineal predictive techniques were applied in this study. Thus, each prediction equation was determined by means of eighteen combinations of sequence acquisition of MRI (SE, GE, T3D), fractal methods for analyzing the obtained MRI (CFA, FTA and OPFTA) and prediction technique of data mining (MLR, IR).

\subsection{Sensory analysis}

Ten dry-cured loins were assessed by a trained panel of thirteen members, using a quantitative descriptive analysis (Antequera et al., 2003). Eleven sensory traits of Iberian dry-cured loins (redness of lean, brightness of lean, marbling, odour intensity, hardness, juiciness, salty taste, flavour intensity, cured flavour, rancid flavour and flavour persistence) were assessed in a nonstructured scale $0-10$. Analyses were developed in tasting rooms with the conditions specified in UNE-EN ISO 8589:2010 regulation. All sessions were conducted at room temperature $\left(22^{\circ} \mathrm{C}\right)$ equipped with white fluorescent lighting $(220-230 \mathrm{~V}, 35 \mathrm{~W})$. The software used to record scores in the sensory sessions was FIZZ Network (version 2.20, Biosystems, France). For each loin, two slices 


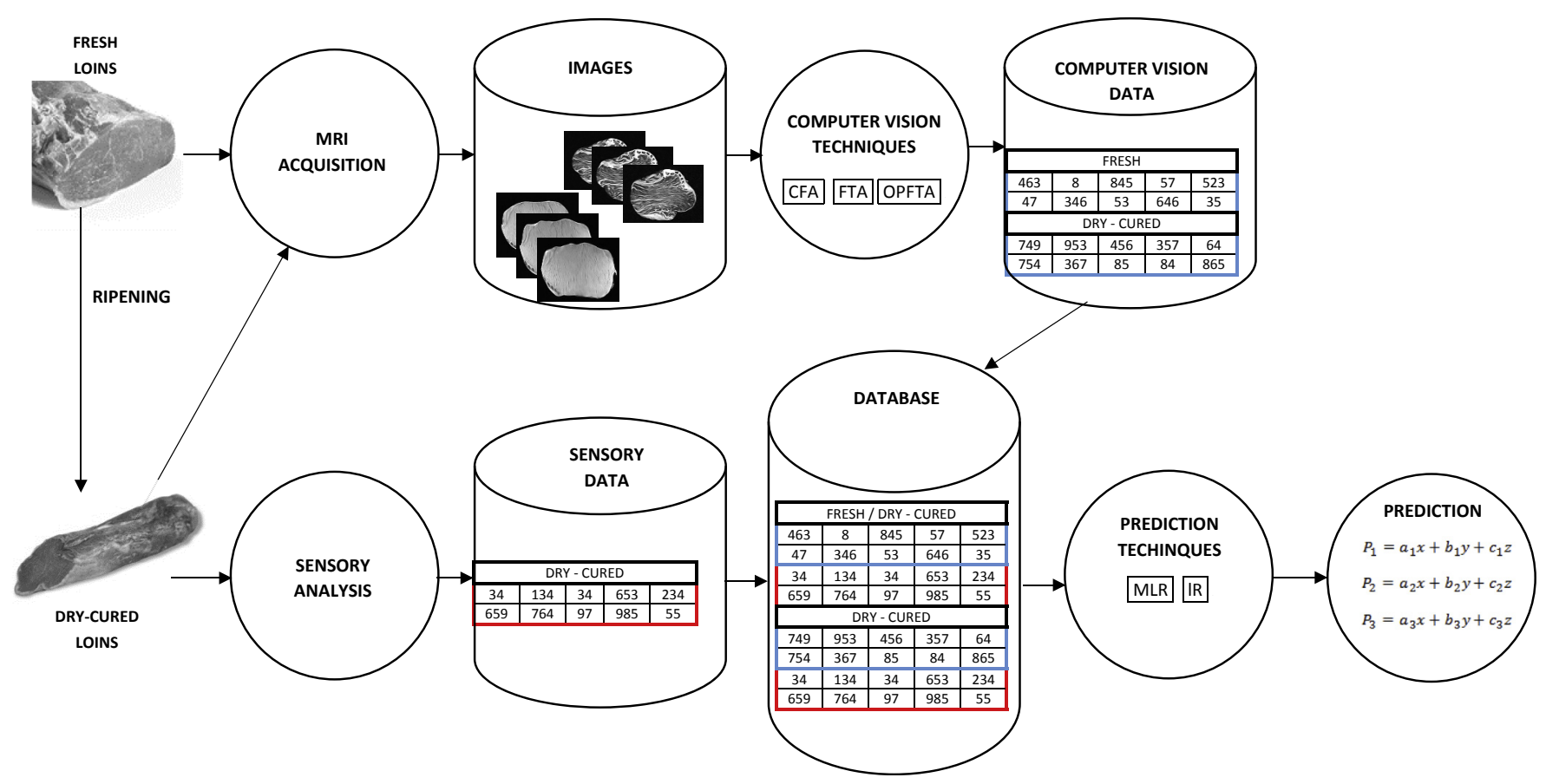

Fig. 1. Experimental design.

$(1.5 \mathrm{~mm})$ were given to the panellists. Slices were obtained using a commercial slicing machine and served on plates to panellists at room temperature. The panel sessions were held mid-morning, about $4 \mathrm{~h}$ after breakfast. Three samples randomly presented to the panellist were analysed in each session. About $200 \mathrm{ml}$ of water at room temperature was provided to the panellists. In each session, the panel average for each sample was recorded.

\subsection{MRI acquisition}

MRI images were generated at the "Animal Source Foodstuffs Innovation Services" (SiPA) of the Faculty of Veterinary Science at University of Extremadura (Cáceres, Spain). A low-field MRI scanner (ESAOTE VET-MR E-SCAN XQ 0.18 T) with a hand/wrist coil was used. Three different T1-weighted sequences were tested: Gradient Echo (GE), Spin Echo (SE) and Turbo 3D (T3D).

In $\mathrm{GE}$, the MR signal is refocused by inverting the gradient instead of using a $180^{\circ}$ radiofrequency (RF) pulse. GE sequences are characterized by a strong signal-to-noise $(\mathrm{S} / \mathrm{N})$ ratio. The following parameters were used: field-of-view (FOV): $160 \times 160 \mathrm{~mm}$; echo time (TE): $14 \mathrm{~ms}$; slice thickness: $4 \mathrm{~mm}$; flip angle: $75^{\circ}$; repetition time (TR): $1450 \mathrm{~ms}$; matrix size: $224 \times 176$; phase encode: 176 ; number of acquisitions: nine per sample. Seventeen slices per loin were obtained, which required $38 \mathrm{~min}$. Three hundred and forty images were obtained for this acquisition sequence.

In $\mathrm{SE}$, a $90^{\circ} \mathrm{RF}$ excitation pulse is followed by a $180^{\circ} \mathrm{RF}$ refocusing pulse to eliminate static magnetic field dissimilarity. The following parameters were used: FOV: $150 \times 150 \mathrm{~mm}$; TE: $26 \mathrm{~ms}$; slice thickness: $4 \mathrm{~mm}$; flip angle: $90^{\circ}$; TR: $630 \mathrm{~ms}$; matrix size: $256 \times 204$; phase encode: 204 ; number of acquisition: five per sample. Twenty-nine slices per loin were obtained and the MRI acquisition took $50 \mathrm{~min}$ for each loin. Five hundred and eighty images were obtained for this acquisition sequence.

The T3D sequence is a GE sequence in which a special second encoding in the direction of the selection gradient enables 3D reconstruction. The $\mathrm{S} / \mathrm{N}$ ratio is also high in this type of sequence. The following parameters were used: FOV: $180 \times 180 \times 140 \mathrm{~mm}$;
TE: $16 \mathrm{~ms}$; slice thickness: $1.1 \mathrm{~mm}$; flip angle: $65^{\circ}$; TR: $38 \mathrm{~ms}$; matrix size: $192 \times 176$ x 92; phase encode: 16192; number of acquisition: four per sample. One hundred and twenty-two slices per loin were obtained and the analysis requires $56 \mathrm{~min}$ for each loin. Two thousand, four hundred and forty images were obtained for this acquisition sequence.

For all sequences, the MRI acquisition was performed at $23^{\circ} \mathrm{C}$. All images were acquired in DICOM format with $512 \times 512$ resolution and 256 grey levels.

\subsection{Computer vision techniques}

After the MRI images of the loins were obtained, they were analysed by three computer vision algorithms based on fractal (CFA, FTA and OPFTA). Thus, numerical data are obtained from the images.

The first one, CFA (Mandelbrot, 1982) studies the pattern of repetition in the image. The method measures the number of boxes (small fractions of the image depending on the size of the original image) needed to cover an area occupied by the object as a function of the size of boxes. This is calculated by computing the so-called local exponent with different box sizes. The local exponent, D, is the variation of the number of objects $(\mathrm{N})$ depending on the box size (R).

$D=-\frac{\Delta \ln N}{\Delta \ln R}$

The fractal dimension is the value of the number of $\mathrm{D}$ when it remains constant respect to the box size. Quantification of the fractal dimension of each simple image was calculated using the compression box counting package (toolbox downloaded from http://www.mathworks.com/matlabcentral/fileexchange/13063boxcount - last accessed December 2017, for MATLAB (The Mathworks Inc. Natick, Massachusetts, U.S.A.)). A total of nine fractal dimensions were computed in this algorithm: BOX1, BOX2, BOX3, BOX4, BOX5, BOX6, BOX7, BOX8 and BOX9.

The second one, FTA (Caballero et al., 2017b) is a novelty texture 
algorithm based on fractal characteristics that are obtained from a two-dimensional variation of Minkowski-Bouligand algorithm (Mandelbrot, 1982). The fractal characteristics reflect the number of times that a pattern is repeated in each image depending of box size calculated in each case. The fractal characteristics were gathered to create a vector. Each vector was computed based on second order statistics, obtaining ten computational texture features on each one: Uniformity (UNI), Entropy (ENT), Correlation (COR), Inverse Difference Moment (IDM), Inertia (INE), Contrast (CON), Emphasis (EMP), Jorna's Correlation (JC), Cluster shade (CS) and Cluster Prominence (CP) (Aggarwal and Agrawal, 2012; Packingpaugh et al., 1991).

The last one, OPFTA (Caballero et al., 2017c), is a novel texture algorithm based on features obtained from fractal values. Before applying this algorithm, the largest area rectangle inscribed in the contour of the loin was selected (Molano et al., 2012). Later, each rectangle was divided into smaller rectangles of $32 \times 32$ pixels, so called, region of interests (ROI). Then, a two-dimensional variation of the Minkowski-Bouligand algorithm (Mandelbrot, 1982) was applied on each ROI in order to achieve the local exponents with the different box sizes (powers of 2). From all local exponent, the local exponent with the box size equal to eight was selected, this is the most representative one. After that, a matrix with the values of the most representative local exponent of each ROI was gathered. Finally, seven texture features were computed on each matrix: Uniformity (UNI), Entropy (ENT), Correlation (COR), Homogeneity (HOM), Inertia (INE), Contrast (CON) and Efficiency (EFI) (Aggarwal and Agrawal, 2012; Packingpaugh et al., 1991).

\subsection{Prediction techniques}

Predictive techniques of data mining (Multiple Linear Regression (MLR) and Isotonic Regression (IR)) were applied on the two databases constructed: one with results from sensory analysis of dry-cured loins and from MRI analysis of fresh loins, and the other one with results from sensory and MRI analysis of dry-cured loins. In these techniques, future models can be predicted from current data using trend analysis (Witten and Frank, 2005; Wu et al., 2008).

The free software WEKA (Waikato Enviroment for Knowledge Analysis) (http://www.cs.waikato.ac.nz/ml/weka/- last accessed December 2017) was used to perform the predictive analysis.

MLR models the linear relationship between a target variable and more independent prediction variables. It produces a linear regression equation that can be used to predict future values (Hastie et al., 2001). M5 method of attribute selection were applied, this method is based on stepping through the attributes, being the one with the smallest standardized coefficient removed until no improvement is observed in the estimation of the error (Kira and Rendell, 1992). A ridge value of $1 \times 10^{-4}$ were applied too.

IR provides a set of values from the information stored on a database. It is based on estimating the ordered values for an independent variable as a function of one of the input parameters. Only the input parameters providing better adjustment results will be selected. Finally, an interpolation function was established (polynomial trend line) to compare the predicted data set with the original values in the database, obtaining the prediction equation (Barlow et al., 1972; Borge, 1985).

The correlation coefficient (R) was used for evaluating the goodness of fit of the prediction and for its validation, according to the Colton rules (Colton, 1974). This author considered $\mathrm{R}$ from 0 to 0.25 as little to no relationship; from 0.25 to 0.5 indicates a weak degree of relationship; from 0.50 to 0.75 indicates a moderate to good relationship; and from 0.75 to 1 indicates a very good to excellent relationship.
$R=\sqrt{\frac{\sum_{i=1}^{n}\left(f_{i}-\bar{y}\right)^{2}}{\sum_{i=1}^{n}\left(y_{i}-\bar{y}\right)^{2}}}$

where $\mathrm{f}_{\mathrm{i}}$ is the predicted value, $\mathrm{y}_{\mathrm{i}}$ is the real value and $\bar{y}$ is the average value.

Additionally, the mean absolute error (MAE) (Hyndman and Koehler, 2006) was used to validate the prediction results too. Values of MAE less than 2 are appropriate (Hyndman, 2006). It is calculated by the following equation:

$M A E=\frac{1}{n} \sum_{i=1}^{n}\left|f_{i}-y_{i}\right|$

where $f_{i}$ is the predicted value and $y_{i}$ is the real value.

\subsection{Statistical analysis}

Predicted and real data of sensory attributes were compared by using one-way analysis of variance (ANOVA) using the general linear model procedure. Statistical analyses were performed using the SPSS package software (v. 20.0) (IBM Co. New York, New York, U.S.A.).

\subsection{Canonical correlation analysis}

Canonical correlation analyses are used to identify and measure the associations between two sets of variables (Hotelling, 1936). For that, a Principal Component Analysis (PCA) was applied to evaluate the relationship between the computational texture features and the sensory attributes. Canonical correlation analyses were carried out using the SPSS package software (v. 20.0) (IBM Co. New York, New York, U.S.A.).

\section{Results and discussion}

\subsection{Features for databases}

Regarding to data from sensory analysis of dry-cured loins, average scores obtained by sensory traits of appearance were 7.09 , 4.63 and 6.73 for redness of lean, brightness of lean and marbling, respectively. As for attributes related to texture, hardness and juiciness were scored with 5.30 and 5.85, respectively. Odour intensity achieved a value of 6.68. Average score for salty taste was 5.08. Sensory attributes of flavour: intensity, persistence, cured and rancid reached $6.67,5.62,6.14$ and 1.87 , respectively.

Results on sensory analysis of Iberian dry-cured loins of this study are quite in concordance with previous studies (Antequera et al., 2003; Caballero et al., 2017a; Cernadas et al., 2001, 2005; Muriel et al., 2004). The attributes most appreciated by consumers (redness of lean, marbling, juiciness, odour intensity, cured flavour and flavour intensity) obtained scores higher than 6 . These features show a notably influence on the acceptability of the products (Ruiz et al., 2002).

In relation to data from MRI analysis, Tables 1 and 2 show mean values of the features of the three fractal algorithms applied for analysing MRI of fresh and dry-cured loins acquired with three different sequences, respectively. There were significant differences in the values of all features among SE, GE and T3D acquisition sequences for both cases, fresh and dry-cured loins. In agreement, Pérez-Palacios et al. (2015) and Caballero et al. (2016a) found the significant effect of the acquisition sequences on the values of the computational texture features of MRI from loins. The differences 
Table 1

Values of the features of different fractal algorithms at analysing MRI of fresh loins acquired by different sequences ${ }^{\mathrm{a}}$.

\begin{tabular}{|c|c|c|c|c|c|}
\hline & & SE & GE & T3D & $\mathrm{p}$ (SE vs GE vs T3D) \\
\hline \multirow[t]{9}{*}{ CFA } & BOX1 & 7.482 & 7.326 & 7.437 & $<0.001$ \\
\hline & BOX2 & 7.380 & 7.234 & 7.355 & $<0.001$ \\
\hline & BOX3 & 5.225 & 5.090 & 5.245 & $<0.001$ \\
\hline & BOX4 & 6.212 & 6.030 & 6.226 & $<0.001$ \\
\hline & BOX5 & 5.296 & 5.001 & 5.241 & $<0.001$ \\
\hline & BOX6 & 7.295 & 6.956 & 7.244 & $<0.001$ \\
\hline & BOX7 & 6.211 & 5.874 & 6.238 & $<0.001$ \\
\hline & BOX8 & 1.609 & 1.342 & 1.612 & $<0.001$ \\
\hline & BOX9 & 6.257 & 5.955 & 5.952 & $<0.001$ \\
\hline \multirow[t]{10}{*}{ FTA } & UNI & 142.214 & 134.985 & 169.401 & $<0.001$ \\
\hline & ENT & 12.205 & 11.756 & 13.912 & $<0.001$ \\
\hline & COR & 1.967 & 2.118 & 1.302 & $<0.001$ \\
\hline & IDM & 6.208 & 6.060 & 6.773 & $<0.001$ \\
\hline & INE & 295.472 & 295.177 & 296.602 & $<0.001$ \\
\hline & $\mathrm{CON}$ & 418.214 & 410.985 & 445.400 & $<0.001$ \\
\hline & EMP & 12.012 & 11.717 & 13.141 & $<0.001$ \\
\hline & $\mathrm{JC}$ & 154.285 & 154.866 & 151.913 & $<0.001$ \\
\hline & CS & 797.278 & 811.054 & 744.210 & $<0.001$ \\
\hline & $\mathrm{CP}$ & 4878.206 & 4967.638 & 4351.129 & $<0.001$ \\
\hline \multirow[t]{7}{*}{ OPFTA } & UNI & 146.373 & 55.259 & 50.734 & $<0.001$ \\
\hline & ENT & 6.336 & 8.779 & 5.435 & $<0.001$ \\
\hline & COR & 50136.087 & 3232.292 & 5906.577 & $<0.001$ \\
\hline & HOM & 15.845 & 9.211 & 7.108 & $<0.001$ \\
\hline & INE & 9157.878 & 4085.864 & 3284.801 & $<0.001$ \\
\hline & $\mathrm{CON}$ & 11274.738 & 3659.997 & 3285.068 & $<0.001$ \\
\hline & EFI & 0.301 & 0.504 & 0.394 & $<0.001$ \\
\hline
\end{tabular}

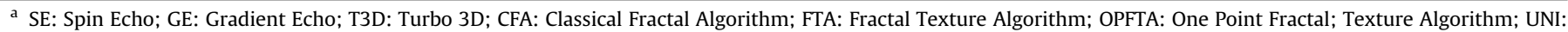

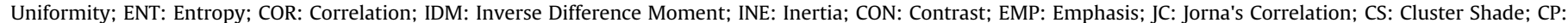
Cluster Prominence; HOM: Homogeneity; EFI: Efficiency

Table 2

Values of the features of different fractal algorithms at analysing MRI of dry-cured loins acquired by different sequences ${ }^{\mathrm{a}}$.

\begin{tabular}{|c|c|c|c|c|c|}
\hline & & SE & GE & T3D & p (SE vs GE vs T3D) \\
\hline \multirow{9}{*}{ CFA } & BOX1 & 7.605 & 7.511 & 7.473 & $<0.001$ \\
\hline & BOX2 & 7.502 & 7.419 & 7.366 & $<0.001$ \\
\hline & BOX3 & 5.324 & 5.259 & 5.186 & $<0.001$ \\
\hline & BOX4 & 6.245 & 6.144 & 6.104 & $<0.001$ \\
\hline & BOX5 & 5.283 & 5.087 & 5.120 & $<0.001$ \\
\hline & BOX6 & 7.344 & 7.078 & 7.174 & $<0.001$ \\
\hline & BOX7 & 6.183 & 5.981 & 6.106 & $<0.001$ \\
\hline & BOX8 & 1.499 & 1.421 & 1.450 & $<0.001$ \\
\hline & BOX9 & 6.416 & 6.313 & 6.151 & $<0.001$ \\
\hline \multirow[t]{10}{*}{ FTA } & UNI & 127.492 & 113.984 & 167.067 & $<0.001$ \\
\hline & ENT & 11.266 & 10.367 & 13.767 & $<0.001$ \\
\hline & COR & 2.346 & 2.796 & 1.351 & $<0.001$ \\
\hline & IDM & 5.895 & 5.591 & 6.725 & $<0.001$ \\
\hline & INE & 294.847 & 294.238 & 296.506 & $<0.001$ \\
\hline & $\mathrm{CON}$ & 403.492 & 389.984 & 443.067 & $<0.001$ \\
\hline & EMP & 11.387 & 10.778 & 13.046 & $<0.001$ \\
\hline & $\mathrm{JC}$ & 155.741 & 157.475 & 152.102 & $<0.001$ \\
\hline & CS & 826.611 & 855.369 & 748.650 & $<0.001$ \\
\hline & $\mathrm{CP}$ & 5073.272 & 5271.077 & 4560.021 & $<0.001$ \\
\hline \multirow[t]{7}{*}{ OPFTA } & UNI & 2.399 & 3.611 & 11.584 & $<0.001$ \\
\hline & ENT & 6.091 & 6.033 & 3.770 & $<0.001$ \\
\hline & COR & 34253.935 & 3677.903 & 9344.372 & $<0.001$ \\
\hline & HOM & 2.745 & 2.809 & 4.870 & $<0.001$ \\
\hline & INE & 117.568 & 149.352 & 118.531 & $<0.001$ \\
\hline & CON & 29.713 & 49.445 & 81.935 & $<0.001$ \\
\hline & EFI & 0.085 & 0.351 & 0.357 & $<0.001$ \\
\hline
\end{tabular}

a See Table 1 for abbreviations.

on the values of the features on all cases and for the three algorithms reveal that the sequence acquisition (and consequently, the images for each type of acquisition sequence) influences on the obtained fractal features.

\subsection{Prediction of sensory traits}

Each sensory attribute of dry-cured loin was determined nondestructively (as a function of MRI data of fresh and dry-cured loins) by means of eighteen combinations of sequence acquisition 
of MRI (SE, GE, T3D), fractal methods for analyzing the obtained MRI (CFA, FTA and OPFTA) and prediction technique of data mining (MLR, IR). The prediction accuracy of these variables was analysed as follow.

Table 3 shows $\mathrm{R}$ values of the prediction equations for sensory attributes of dry-cured loins as a function of MRI data from fresh loins. Taking into consideration the acquisition sequences, SE reached the highest $R$ values when applying FTA and OPFTA algorithms. GE and T3D obtained the highest $R$ values in the case of CFA algorithm. This is observed when applying MLR and IR. Regarding the algorithms, in general, OPFTA gave the best results. However, some specific findings are worth noting: when using SE, similar R values were obtained by OPFTA and FTA for most sensory attributes; when using GE and T3D, CFA gave the highest $R$ values in some sensory attributes. Comparing MLR and IR, in general, MLR offered slightly higher $\mathrm{R}$ values than IR. Thus, the best combination for predicting sensory attributes of dry-cured loin as a function of MRI data from fresh loin could be: SE as acquisition sequence; OPFTA for MRI analysis; and MLR as predictive technique. Nevertheless, considering that $\mathrm{R}$ values higher than 0.5 offer acceptable relationship (Colton, 1974), the following combinations could also be applied: GE-CFA, T3D-CFA, SE-FTA, GE-OPFTA and SE-OPFTA, when applying MLR as data mining technique; and GE-CFA, T3D-

Table 3

Correlation coefficient $(R)$ of the prediction equations of sensory attributes of drycured loins as a function of MRI data from fresh loin. Different sequence acquisition (GE, SE, T3D), fractal algorithms (CFA, FTA, OPFTA) and predictive technique (MLR, IR) were tested ${ }^{\mathrm{a}}$.

\begin{tabular}{|c|c|c|c|c|c|c|c|}
\hline & & \multicolumn{3}{|l|}{ MLR } & \multicolumn{3}{|l|}{ IR } \\
\hline & & CFA & FTA & OPFTA & CFA & FTA & OPFTA \\
\hline \multirow[t]{3}{*}{ Redness of lean } & GE & 0.646 & 0.421 & 0.751 & 0.502 & 0.329 & 0.665 \\
\hline & SE & 0.311 & 0.710 & 0.866 & 0.321 & 0.626 & 0.698 \\
\hline & T3D & 0.556 & 0.160 & 0.711 & 0.490 & 0.310 & 0.542 \\
\hline \multirow[t]{3}{*}{ Brightness of lean } & GE & 0.607 & 0.461 & 0.697 & 0.627 & 0.388 & 0.493 \\
\hline & SE & 0.584 & 0.720 & 0.772 & 0.496 & 0.667 & 0.727 \\
\hline & T3D & 0.603 & 0.367 & 0.379 & 0.538 & 0.260 & 0.377 \\
\hline \multirow[t]{3}{*}{ Marbling } & GE & 0.621 & 0.681 & 0.834 & 0.620 & 0.378 & 0.207 \\
\hline & SE & 0.299 & 0.771 & 0.865 & 0.356 & 0.631 & 0.649 \\
\hline & T3D & 0.731 & 0.144 & 0.278 & 0.533 & 0.291 & 0.604 \\
\hline \multirow[t]{3}{*}{ Odour intensity } & GE & 0.642 & 0.529 & 0.653 & 0.533 & 0.480 & 0.578 \\
\hline & SE & 0.474 & 0.676 & 0.788 & 0.404 & 0.644 & 0.697 \\
\hline & T3D & 0.590 & 0.406 & 0.416 & 0.527 & 0.390 & 0.616 \\
\hline \multirow[t]{3}{*}{ Hardness } & GE & 0.586 & 0.167 & 0.795 & 0.518 & 0.353 & 0.478 \\
\hline & SE & 0.214 & 0.702 & 0.806 & 0.293 & 0.667 & 0.681 \\
\hline & T3D & 0.603 & 0.104 & 0.265 & 0.511 & 0.097 & 0.602 \\
\hline \multirow{3}{*}{ Juiciness } & GE & 0.667 & 0.588 & 0.828 & 0.667 & 0.557 & 0.674 \\
\hline & SE & 0.353 & 0.741 & 0.881 & 0.371 & 0.675 & 0.781 \\
\hline & T3D & 0.623 & 0.167 & 0.488 & 0.550 & 0.353 & 0.620 \\
\hline \multirow[t]{3}{*}{ Salty taste } & GE & 0.578 & 0.367 & 0.503 & 0.632 & 0.341 & 0.329 \\
\hline & SE & 0.561 & 0.735 & 0.756 & 0.448 & 0.690 & 0.716 \\
\hline & T3D & 0.521 & 0.193 & 0.717 & 0.248 & 0.214 & 0.296 \\
\hline \multirow[t]{3}{*}{ Flavor intensity } & GE & 0.676 & 0.331 & 0.737 & 0.623 & 0.153 & 0.547 \\
\hline & SE & 0.603 & 0.769 & 0.788 & 0.467 & 0.734 & 0.740 \\
\hline & T3D & 0.580 & 0.366 & 0.336 & 0.561 & 0.225 & 0.524 \\
\hline \multirow[t]{3}{*}{ Flavor persistence } & GE & 0.606 & 0.372 & 0.731 & 0.692 & 0.477 & 0.663 \\
\hline & SE & 0.500 & 0.735 & 0.761 & 0.448 & 0.719 & 0.745 \\
\hline & T3D & 0.448 & 0.304 & 0.474 & 0.537 & 0.225 & 0.393 \\
\hline \multirow[t]{3}{*}{ Cured flavor } & GE & 0.623 & 0.629 & 0.412 & 0.544 & 0.488 & 0.430 \\
\hline & SE & 0.604 & 0.784 & 0.792 & 0.533 & 0.545 & 0.649 \\
\hline & T3D & 0.440 & 0.376 & 0.133 & 0.478 & 0.246 & 0.415 \\
\hline \multirow[t]{3}{*}{ Rancid flavor } & GE & 0.644 & 0.523 & 0.730 & 0.469 & 0.308 & 0.530 \\
\hline & SE & 0.309 & 0.765 & 0.915 & 0.319 & 0.620 & 0.778 \\
\hline & T3D & 0.444 & 0.152 & 0.598 & 0.504 & 0.204 & 0.496 \\
\hline
\end{tabular}

a See Table 1 for abbreviations.
CFA, SE-FTA and SE-OPFTA in the case of applying IR.

Table 4 shows values of $R$ for the prediction equations of sensory attributes of dry-cured loins as a function of MRI data from drycured loins. Considering the acquisition sequences, in general, GE and SE produced the highest $R$ values. However, it is noted that GE offered the highest $R$ values when using CFA, whereas SE is the best for FTA and OPFTA. As for the fractal algorithm, OPFTA showed the highest $\mathrm{R}$ values for the three acquisition sequences. Nevertheless, FTA and CFA also allowed acceptable $R$ values for most sensory attributes. In relation to the predictive technique of data mining, again, MLR gave slightly higher R values than IR. Consequently, the most accurate combination of sequence acquisition, fractal algorithm for MRI analysis and predictive technique for prediction sensory attributes of dry-cured loin as a function of MRI data from dry-cured loin should be SE, OPFTA and MLR. This is the same combination indicated when prediction is made as a function of MRI data from fresh loin. In addition, there are more combinations offering acceptable $R$ values ( $R>0.5$ ) (Colton, 1974): GE-CFA, GEFTA, SE-FTA, GE-OPFTA, SE-OPFTA and T3D-OPFTA when applying IR, and all combinations except T3D-CFA when applying MLR. These results point out the importance of choosing the appropriate acquisition sequence, fractal algorithm and predictive technique of data mining for prediction sensory attributes as a function of MRI

Table 4

Correlation coefficient $(R)$ of the prediction equations of sensory attributes of drycured loins as a function of MRI data from dry-cured loin. Different sequences acquisition (GE, SE, T3D), fractal algorithms (CFA, FTA, OPFTA) and predictive technique (MLR, IR) were tested ${ }^{\mathrm{a}}$.

\begin{tabular}{|c|c|c|c|c|c|c|c|}
\hline & & \multicolumn{3}{|l|}{ MLR } & \multicolumn{3}{|l|}{ IR } \\
\hline & & CFA & FTA & OPFTA & CFA & FTA & OPFTA \\
\hline \multirow[t]{3}{*}{ Redness of lean } & GE & 0.843 & 0.787 & 0.925 & 0.732 & 0.722 & 0.853 \\
\hline & SE & 0.689 & 0.858 & 0.974 & 0.635 & 0.818 & 0.960 \\
\hline & T3D & 0.386 & 0.613 & 0.628 & 0.298 & 0.507 & 0.584 \\
\hline \multirow[t]{3}{*}{ Brightness of lean } & GE & 0.793 & 0.543 & 0.892 & 0.498 & 0.542 & 0.712 \\
\hline & SE & 0.594 & 0.786 & 0.928 & 0.491 & 0.758 & 0.771 \\
\hline & T3D & 0.445 & 0.555 & 0.561 & 0.348 & 0.535 & 0.525 \\
\hline \multirow[t]{3}{*}{ Marbling } & GE & 0.642 & 0.837 & 0.961 & 0.699 & 0.690 & 0.856 \\
\hline & SE & 0.606 & 0.855 & 0.980 & 0.610 & 0.802 & 0.968 \\
\hline & T3D & 0.306 & 0.594 & 0.623 & 0.429 & 0.580 & 0.588 \\
\hline \multirow[t]{3}{*}{ Odour intensity } & GE & 0.692 & 0.608 & 0.852 & 0.563 & 0.577 & 0.665 \\
\hline & SE & 0.610 & 0.794 & 0.891 & 0.500 & 0.622 & 0.745 \\
\hline & T3D & 0.413 & 0.397 & 0.641 & 0.457 & 0.370 & 0.583 \\
\hline \multirow[t]{3}{*}{ Hardness } & GE & 0.642 & 0.799 & 0.855 & 0.580 & 0.723 & 0.741 \\
\hline & SE & 0.606 & 0.951 & 0.960 & 0.494 & 0.725 & 0.935 \\
\hline & T3D & 0.316 & 0.568 & 0.583 & 0.244 & 0.508 & 0.588 \\
\hline \multirow[t]{3}{*}{ Juiciness } & GE & 0.744 & 0.817 & 0.858 & 0.686 & 0.720 & 0.871 \\
\hline & SE & 0.628 & 0.940 & 0.983 & 0.505 & 0.797 & 0.957 \\
\hline & T3D & 0.524 & 0.576 & 0.620 & 0.475 & 0.555 & 0.564 \\
\hline \multirow[t]{3}{*}{ Salty taste } & GE & 0.644 & 0.730 & 0.875 & 0.589 & 0.591 & 0.765 \\
\hline & SE & 0.503 & 0.778 & 0.903 & 0.499 & 0.624 & 0.784 \\
\hline & T3D & 0.498 & 0.459 & 0.663 & 0.259 & 0.419 & 0.544 \\
\hline \multirow[t]{3}{*}{ Flavor intensity } & GE & 0.733 & 0.784 & 0.825 & 0.548 & 0.551 & 0.672 \\
\hline & SE & 0.655 & 0.893 & 0.925 & 0.439 & 0.666 & 0.838 \\
\hline & T3D & 0.413 & 0.515 & 0.662 & 0.368 & 0.400 & 0.559 \\
\hline \multirow[t]{3}{*}{ Flavor persistence } & GE & 0.650 & 0.688 & 0.727 & 0.534 & 0.592 & 0.617 \\
\hline & SE & 0.497 & 0.765 & 0.867 & 0.412 & 0.647 & 0.830 \\
\hline & T3D & 0.366 & 0.461 & 0.657 & 0.305 & 0.325 & 0.564 \\
\hline \multirow[t]{3}{*}{ Cured flavor } & GE & 0.579 & 0.683 & 0.739 & 0.599 & 0.568 & 0.677 \\
\hline & SE & 0.480 & 0.765 & 0.908 & 0.317 & 0.400 & 0.896 \\
\hline & T3D & 0.375 & 0.388 & 0.495 & 0.223 & 0.309 & 0.419 \\
\hline \multirow[t]{3}{*}{ Rancid flavor } & GE & 0.801 & 0.853 & 0.908 & 0.531 & 0.764 & 0.775 \\
\hline & SE & 0.720 & 0.796 & 0.960 & 0.508 & 0.756 & 0.857 \\
\hline & T3D & 0.467 & 0.548 & 0.684 & 0.403 & 0.452 & 0.681 \\
\hline
\end{tabular}

\footnotetext{
a See Table 1 for abbreviations.
} 
data. It could be explained by the different $\mathrm{S} / \mathrm{N}$ ratio of $\mathrm{SE}$ in comparison to GE and T3D (Caballero et al., 2017a). It seems that SE should be used as sequence acquisition.

In fact, SE is the most widely used acquisition sequence of MRI for meat products in the scientific literature (Antequera et al., 2003, 2007; Caballero et al., 2016a, 2016b; 2017a; Cernadas et al., 2001, 2005; Fantazzini et al., 2009; Manzoco et al., 2013; Pérez-Palacios et al., 2010b; 2011). It could be ascribed to the better performance in terms of $\mathrm{S} / \mathrm{N}$ ratio of $\mathrm{SE}$ in comparison to GE and T3D. OPFTA could be a good solution for MRI analysis. It is more efficient in terms of computational complexity than CFA and FTA, since OPFTA has a lower number of features than CFA and FTA (PérezPalacios et al., 2017b). Regarding the predictive technique, it should be recommended the use of MLR. In fact, this technique is indicated when the values of the database are lowly correlated (Pérez-Palacios et al., 2014). In addition to this, MLR has showed high accuracy for prediction physico-chemical and sensory attributes of meat products in several works (Caballero et al., 2016a, 2016b, 2017a; Pérez-Palacios et al., 2014).

\subsection{Validation of prediction}

As the most accurate combination is proposed SE as acquisition sequence, OPFTA as fractal algorithm for MRI analysis and MLR as

Table 5

Correlation coefficient (R) and Mean Absolute Error (MAE) of sensory attributes between real (by means of sensory analyses) and predicted (by means of best prediction equations as a function of MRI data from fresh and dry-cured loin) values.

\begin{tabular}{llllll}
\hline & \multicolumn{2}{l}{ FRESH LOINS } & & \multicolumn{2}{l}{ DRY-CURED LOINS } \\
\cline { 2 - 3 } \cline { 5 - 6 } & $\mathrm{R}$ & $\mathrm{R}$ & & $\mathrm{R}$ & $\mathrm{MAE}$ \\
\hline Redness of lean & 0.744 & 0.615 & & 0.963 & 0.196 \\
Brightness of lean & 0.702 & 0.353 & & 0.883 & 0.226 \\
Marbling & 0.740 & 1.499 & & 0.976 & 0.547 \\
Odour intensity & 0.674 & 0.408 & & 0.839 & 0.296 \\
Hardness & 0.645 & 0.758 & & 0.932 & 0.421 \\
Juiciness & 0.759 & 0.648 & & 0.961 & 0.258 \\
Salty taste & 0.685 & 0.335 & & 0.813 & 0.257 \\
Flavor intensity & 0.713 & 0.241 & & 0.885 & 0.109 \\
Flavor persistence & 0.705 & 0.197 & & 0.831 & 0.198 \\
Cured flavor & 0.704 & 0.286 & & 0.806 & 0.306 \\
Rancid flavor & 0.860 & 0.202 & 0.929 & 0.123 \\
\hline
\end{tabular}

predictive technique of data mining. In order to validate the prediction equations obtained, $\mathrm{R}$ and MAE were calculated between real (by means of sensory analyses of dry-cured loins) and predicted (by means of the prediction equations) values of sensory attributes (Table 5).

When prediction is made as a function of MRI data from fresh loins, $R$ values vary from 0.645 to 0.860 and MAE is between 0.197 and 1.499. In the case of predicting as a function of MRI data from dry-cured loins, values of MAE vary from 0.109 to 0.547 and $R$ values are higher than 0.800 . In both cases, $R$ was higher than 0.5 and MAE lower than 2, being within the limit of acceptable values (Colton, 1974).

In addition, average values of sensory attributes determined by sensory analysis and predicted as a function of MRI data from fresh and dry-cured loins were statistically compared, as can be observed in Figs. 2 and 3, respectively. No significant differences were found between real and predicted values in both cases for all sensory attributes. These results ratify the validity of prediction sensory attributes of dry-cured loin as a function of MRI data (from both fresh and dry-cured loins) by means of SE as acquisition sequence of MRI, OPFTA as fractal algorithm for MRI analysis and MLR as predictive technique of data mining. At this point, the following step would be to implement this methodology and develop a computer system to make this process automatic and easily practiced.

The advantage of using data mining tools as WEKA is that calibration and validation are achieved by using the same data sets, not being necessary to perform the validation with a different data set. This also allows the development of the prediction model (Harrell Jr. et al., 1996).

As example, Table 6 shows the prediction equations of sensory attributed of dry-cured loins obtained when applying SE-OPFTAMLR. As can be seen, the number of independent variables (features from OPFTA algorithm) of the prediction equations were between three (brightness of lean) to six (odour intensity, flavour intensity, flavour persistence and cured flavour) features when prediction is made as a function of MRI data from fresh loins, being the most usual ENT, COR, HOM and EFI. In the case of prediction as a function of MRI data from dry-cured loins, the prediction equations are composed by between one (flavour persistence) to six (redness of lean, marbling, hardness and juiciness) features, being the most common UNI, ENT, HOM and INE.

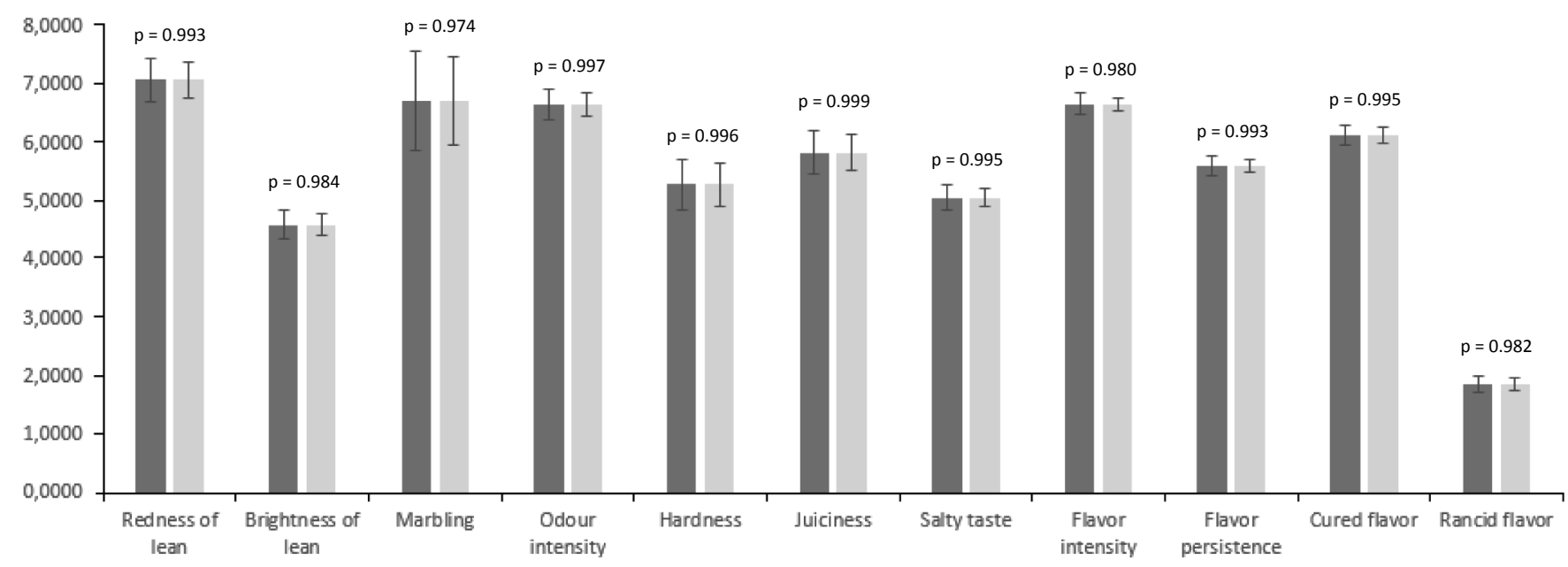

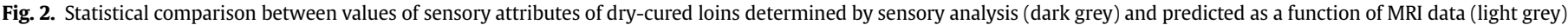
from fresh loins. 


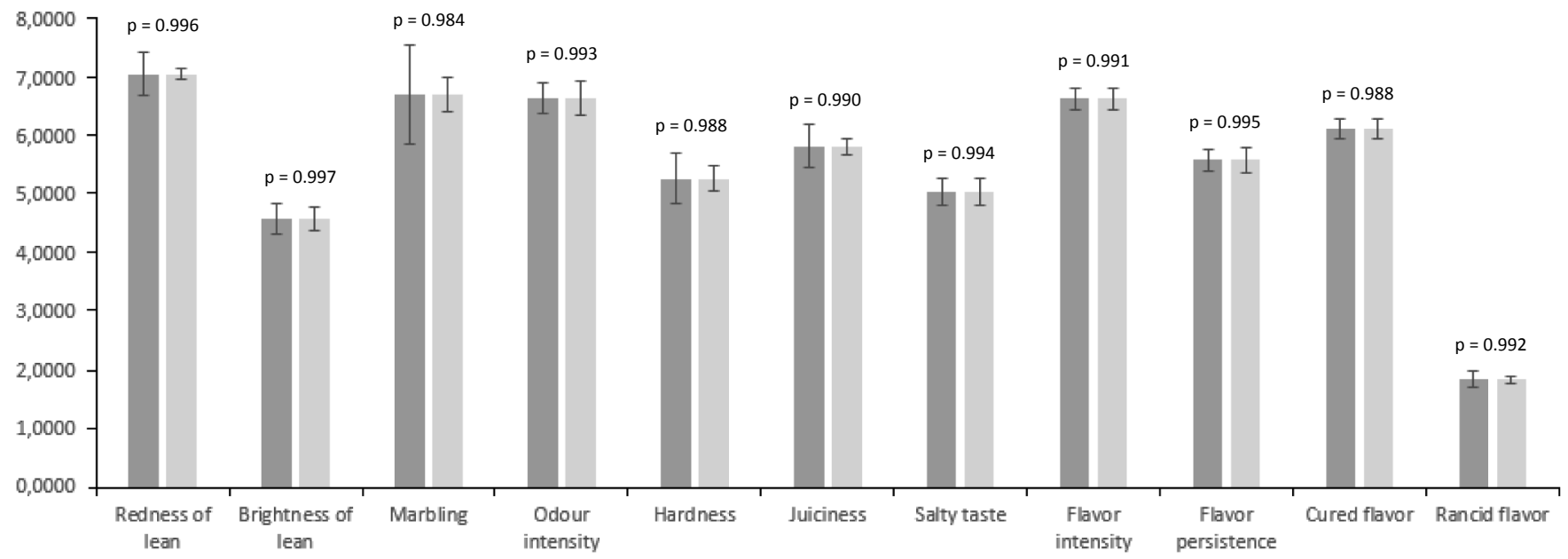

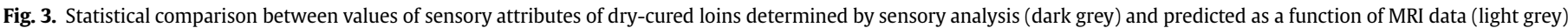
from dry-cured loins.

\section{Table 6}

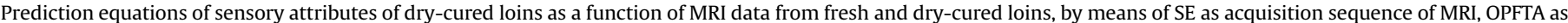
fractal algorithm for MRI analysis and MLR as predictive technique of data mining .

\begin{tabular}{|c|c|c|}
\hline & Fresh loin & Dry-cured loin \\
\hline Redness of lean $=$ & $\begin{array}{l}5.324 \times \mathrm{ENT}-1.218 \times \mathrm{COR}+1.206 \times \mathrm{HOM}+1.416 \times \\
\mathrm{CON}+4.973^{*} \mathrm{EFI}+1.699\end{array}$ & $\begin{array}{l}135.980 \times \mathrm{UNI}-57.554 \times \mathrm{ENT}+12.506 \times \mathrm{HOM}+231.693 \times \mathrm{INE}-935.716 \times \\
\mathrm{CON}+3.686 \times \mathrm{EFI}+55.281\end{array}$ \\
\hline Brightness of lean $=$ & $1.258 \times \mathrm{COR}+2.058 \times \mathrm{HOM}-4.382 \times \mathrm{EFI}+3.828$ & $\begin{array}{l}-218.882 \times \mathrm{UNI}+15.303 \times \mathrm{ENT}+8.689 \times \mathrm{HOM}-156.284 \times \mathrm{INE}+906.172 \times \\
\mathrm{CON}-8.354\end{array}$ \\
\hline Marbling $=$ & $\begin{array}{l}-8.775 \times \mathrm{ENT}+3.004 \times \mathrm{COR}-4.090 \times \mathrm{INE}-9.972 \times \\
\mathrm{EFI}+15.716\end{array}$ & $\begin{array}{l}-363.944 \times \mathrm{UNI}+131.942 \times \mathrm{ENT}-22.776 \times \mathrm{HOM}-610.568 \times \mathrm{INE}+2543.804 \times \\
\mathrm{CON}-9.472 \times \mathrm{EFI}-103.818\end{array}$ \\
\hline Odour intensity $=$ & $\begin{array}{l}-3.730 \times \mathrm{UNI}-2.110 \times \mathrm{ENT}+1.676 \times \mathrm{COR}+2.653 \times \\
\mathrm{HOM}+1.690 \times \mathrm{CON}-5.427 \times \mathrm{EFI}+7.796\end{array}$ & $\begin{array}{l}-271.379 \times \mathrm{UNI}+21.187 \times \mathrm{ENT}+8.811 \times \mathrm{HOM}-220.101 \times \mathrm{INE}+1237.074 \times \\
\mathrm{CON}-11.134\end{array}$ \\
\hline Hardness $=$ & $\begin{array}{l}7.291 \times \mathrm{ENT}+1.891 \times \mathrm{HOM}+3.799 \times \mathrm{CON}+4.542 \times \\
\mathrm{EFI}-2.632\end{array}$ & $\begin{array}{l}151.731 \times \mathrm{UNI}-65.635 \times \mathrm{ENT}-1.058 \times \mathrm{COR}+13.246 \times \mathrm{HOM}+252.089 \times \\
\mathrm{INE}-1026.391 \times \mathrm{CON}+60.515\end{array}$ \\
\hline Juiciness $=$ & $\begin{array}{l}-4.330 \times \mathrm{ENT}+1.374 \times \mathrm{COR}-1.105 \times \mathrm{INE}-0.946 \times \\
\mathrm{CON}-5.257 \times \mathrm{EFI}+10.205\end{array}$ & $\begin{array}{l}-195.418 \times \mathrm{UNI}+54.848 \times \mathrm{ENT}-6.296 \times \mathrm{HOM}-279.492 \times \mathrm{INE}+1224.252 \times \\
\mathrm{CON}-4.219 \times \mathrm{EFI}-40.141\end{array}$ \\
\hline Salty taste $=$ & $\begin{array}{l}4.872 \times \mathrm{UNI}+4.523 \times \mathrm{ENT}+0.856 \times \mathrm{COR}+1.307 \times \\
\mathrm{HOM}-3.049 \times \mathrm{EFI}-0.150\end{array}$ & $-88.561 \times \mathrm{UNI}+6.232 \times \mathrm{HOM}+4.983$ \\
\hline Flavor intensity $=$ & $\begin{array}{l}0.907 \times \mathrm{UNI}+2.130 \times \mathrm{ENT}+0.931 \times \mathrm{COR}+1.487 \times \\
\mathrm{HOM}+1.536 \times \mathrm{CON}-2.953 \times \mathrm{EFI}+3.809\end{array}$ & $\begin{array}{l}-125.204 \times \mathrm{UNI}+10.458 \times \mathrm{ENT}+3.832 \times \mathrm{HOM}-55.619 \times \mathrm{INE}+364.416 \times \\
\mathrm{CON}-2.201\end{array}$ \\
\hline Flavor persistence $=$ & $\begin{array}{l}2.751 \times \mathrm{UNI}+3.882 \times \mathrm{ENT}+0.895 \times \mathrm{COR}+1.184 \times \\
\mathrm{HOM}+1.841 \times \mathrm{CON}-2.805 \times \mathrm{EFI}+0.985\end{array}$ & $-44.299 \times \mathrm{UNI}+5.798$ \\
\hline Cured flavor $=$ & $\begin{array}{l}1.235 \times \mathrm{ENT}+0.846 \times \mathrm{COR}+1.946 \times \mathrm{HOM}-0.591 \times \\
\mathrm{INE}+0.858 \times \mathrm{CON}-2.683 \times \mathrm{EFI}+4.376\end{array}$ & $-169.945 \times \mathrm{UNI}+11.575 \times \mathrm{HOM}-124.401 \times \mathrm{INE}+763.564 \times \mathrm{CON}+6.065$ \\
\hline Rancid flavor $=$ & $\begin{array}{l}1.125 \times \mathrm{ENT}-0.451 \times \mathrm{COR}+0.305 \times \mathrm{HOM}-0.454 \times \\
\mathrm{INE}+1.713 \times \mathrm{EFI}+0.925\end{array}$ & $-19.656 \times \mathrm{ENT}+7.616 \times \mathrm{HOM}+27.649 \times \mathrm{INE}+18.325$ \\
\hline
\end{tabular}

a See Table 1 for abbreviations.

\subsection{Canonical correlation analysis}

Canonical correlation analysis was run in order to analyse the relationship between MRI data (features of the OPFTA algorithm) and sensory attributes of dry-cured loins.

Fig. 4 shows the similarity map of the sensory attributes and computer vision features, defined by two principal components (PC1 and PC2) accounted for $78 \%$ and $18 \%$, respectively, of the total variance. The seven computational features of the OPFTA fractal algorithm were located in different quadrants of the PCA. EFI, UNI and HOM were in the middle of the upper right quadrant, very near to redness of lean, and with cured flavour, flavour intensity, flavour persistency and odour intensity also located in this quadrant but near to the axis. CON and INE were in the lower right quadrant, near to juiciness and a bit far from marbling. COR was found in the upper left quadrant, near to axis (with low negative values for PC1 and low positive values for PC2), so far from hardness but relative near to salty taste, which is located in the lower negative quadrant but also near to axis (with low negative values for PC1 and low negative values for PC2). ENT was also in the lower negative quadrant (with high negative values for PC2), a bit far from brightness of lean and rancid flavour (with low negative values for PC2). These results could indicate some relationships between computational features of OPTFA fractal algorithm and sensory attributes, with i) EFI, UNI and HOM positively related to redness of lean, ii) CON and INE positively related to juiciness and iii) COR negatively related to salty taste. In ham (Pérez-Palacios et al., 2010), have previously found some relationships between computational texture features of classical methods for analysing MRI and some sensory attributes.

\section{Conclusions}

This study indicates the possibility of analysing MRI of meat products by means of fractal algorithms and its suitability for 


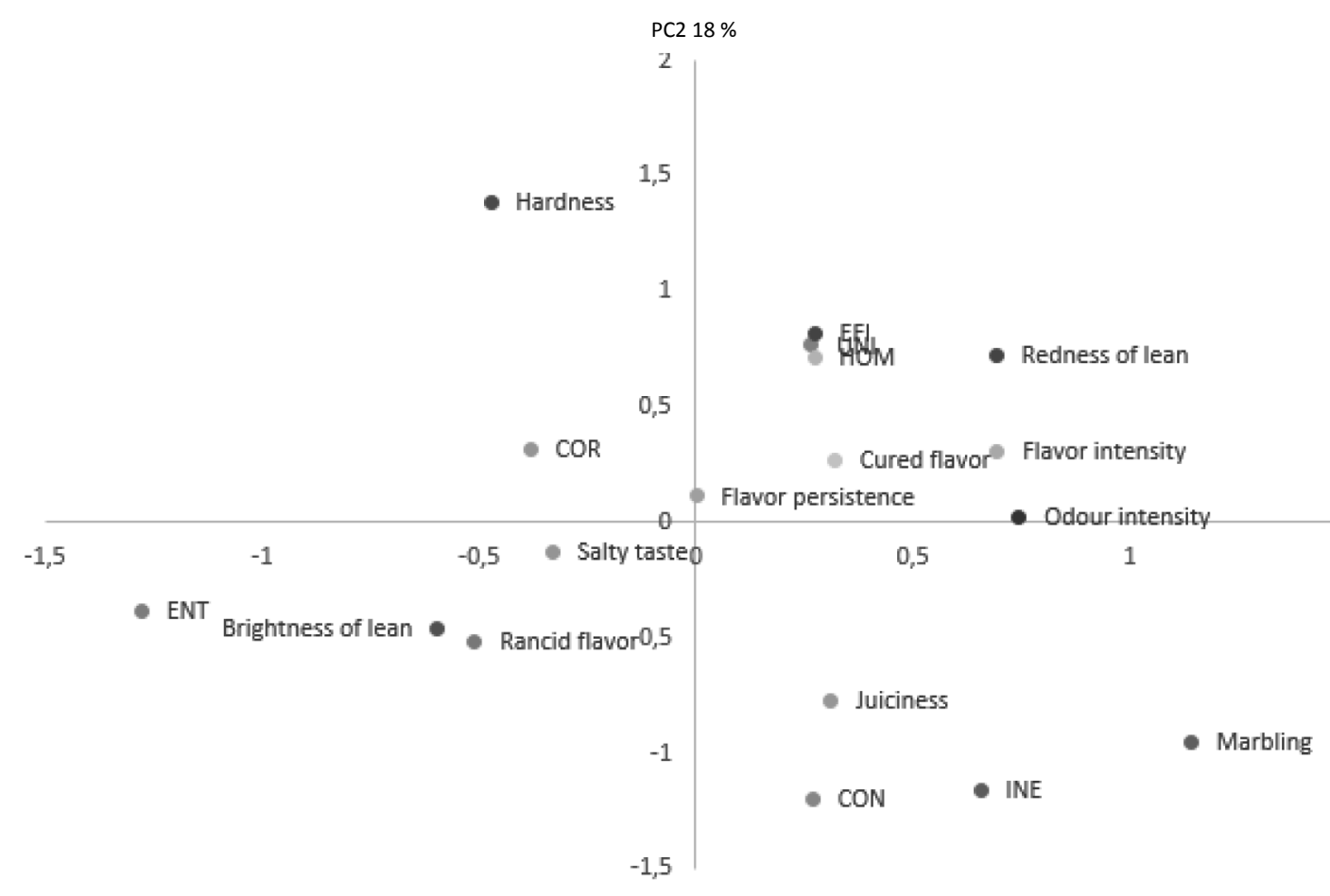

Fig. 4. Variable plot of the Principal Component Analysis of sensory attributes and features from OPTFA algorithm ${ }^{\mathrm{i}}$ of loins. isee Table 1 for abbreviations.

carrying out prediction analysis.

Sensory attributes of dry-cured loins can be predicted as a function of MRI data from both fresh and dry-cured ham. Different combinations of acquisition sequences of MRI, fractal algorithms to analyse MRI and data mining techniques can be applied, being SEOPFTA-MLR the best option.

\section{Acknowledgments}

Daniel Caballero thanks the COST association, Farm Animal Imaging action (FAIM) (COST-FA1102) and the European Social Fund for the grant for a short stay (COST-STSM-FA1102-26642). The authors wish to acknowledge the funding received from the FEDERMICCIN Infrastructure Research Project (UNEX-10-1E-402) and Junta de Extremadura economic support for research group (GRU15113 and GRU15173). We also to thanks the "Montesano" company from Jerez de los Caballeros (Badajoz, Spain), the Animal Source Foodstuffs Innovation Service (SiPA) (Cáceres, Spain) from the University of Extremadura. The authors also wish to thanks to Dr. Francesco Savorani from the Polytechnic University of Turin (Turin, Italy), Dr. Knut Conradsen and Dr. Thomas Martini JØrgensen from the Technical University of Denmark (Kongens Lyngby, Denmark) for their direct contribution and support.

\section{References}

Aggarwal, N., Agrawal, R.K., 2012. First and second order statistics features for classification of magnetic resonance brain images. J. Signal Inf. Process. 3 $574-580$.

Andrés, A.I., Cava, R., Ventanas, J., Thovar, V., Ruiz, J., 2004. Sensory characteristics of Iberian ham: influence of salt content and processing conditions. Meat Sci. 68, 45-51.

Antequera, T., Muriel, E., Rodríguez, P.G., Cernadas, E., Ruiz, J., 2003. Magnetic resonance imaging as a predictive tool for sensory characteristics and intramuscular fat content of dry-cured loin. J. Sci. Food Agric. 83, 268-274.

Antequera, T., Caro, A., Rodriguez, P.G., Pérez, T., 2007. Monitoring the ripening process of Iberian ham by Computer vision on magnetic resonance imaging. Meat Sci. 76, 561-567.
Bajd, F., Skrlep, M., Candek-Potokar, M., Vidmar, J., Sersa, I., 2016. Use of multiparametric magnetic resonance microscopy for discrimination among different processing protocols and anatomical positions of Slovenian dry-cured hams. Food Chem. 197, 1093-1101.

Barlow, R.E., Bartholomew, D., Bremner, J.M., Brunk, H.D., 1972. In: Statistical Inference under Order Restriction: the Theory and Application of Isotonic Regression. Wiley. New York, New York, U.S.A.

Borge, L., 1985. Estimación y contrastes de hipótesis en el modelo lineal general con restricciones de desigualdad. University of Valladolid, Valladolid, Spain. Doctoral thesis.

Caballero, D., Antequera, T., Caro, A., Duran, M.L., Pérez-Palacios, T., 2016a. Data mining on MRI-computational texture features to predict sensory characteristics in ham. Food Bioprocess Technol. 9 (4), 699-708.

Caballero, D., Caro, A., Rodríguez, P.G., Durán, M.L., Ávila, M.M., Palacios, R., Antequera, T., Pérez-Palacios, T., 2016b. Modeling salt difussion in Iberian ham by applying MRI and data mining. J. Food Eng. 189, 115-122.

Caballero, D., Antequera, T., Caro, A., Ávila, M.M., Rodríguez, P.G., Pérez-Palacios, T., 2017a. Non-destructive analysis of sensory traits of dry-cured loins by MRIcomputer vision techniques and data mining. J. Sci. Food Agric. 97, 2942-2952.

Caballero, D., Caro, A., Ávila, M.M., Rodríguez, P.G., Antequera, T., Pérez-Palacios, T., 2017b. New fractal features and data mining to determine food quality based on MRI. IEEE Latin America Transactions 15, 1777-1785.

Caballero, D., Caro, A., Amigo, J.M., Dahl, A.B., Ersboll, B.K., Pérez-Palacios, T., 2017c. Development of a new fractal algorithm to predict quality traits of MRI loins. Lect. Notes Comput. Sci. 10424, 208-217.

Cardenas-Pérez, S., Chanona-Pérez, J.J., Méndez-Méndez, J.V., CalderónDomínguez, G., López-Santiago, R., Arzate-Vázquez, I., 2016. Nanoindetation study on Apple tissue and isolated cells by atomic force microscopy, image and fractal analysis. Innovat. Food Sci. Emerg. Technol. 34, 234-242.

Cernadas, E., Antequera, T., Rodríguez, P.G., Duran, M.L., Gallardo, R., Villa, D., 2001. Magnetic resonance imaging to classify loin from Iberian pig. In: Webb, G.A., Belton, P.S., Gil, A.M., Delgadillo, I. (Eds.), Magnetic Resonance Imaging in Food Science: a View to the Future. Royal Society of Chemistry, Cambridge, United Kingdom, pp. 239-245.

Cernadas, E., Carrión, P., Rodríguez, P.G., Muriel, E., Antequera, T., 2005. Analyzing magnetic resonance images of Iberian pork loin to predict its sensorial characteristics. Comput. Vis. Image Understand. 98, 345-361.

Collell, C., Gou, P., Arnau, J., Comaposada, J., 2011. Non-destructive estimation of moisture, water activity and $\mathrm{NaCl}$ at ham surface during resting and drying using NIR spectroscopy. Food Chem. 129, 601-607.

Colton, T., 1974. In: Statistical in Medicine. Little Brown and Co. New York, New York, U.S.A.

Cortez, P. Portelinha, S., Rodrigues, S., Cadavez, V., Teixeira, A., 2006. Lamb meat quality assessment by support vector machine. Neural Process. Lett. 24, 41-51.

Cortez, P., Cedeira, A., Almeida, F., Matos, T., Reis, J., 2009. Modeling wine 
preferences by data mining from physico-chemical properties. Decis. Support Syst. 47 (4), 547-553.

Dissing, B.S., Papadopoulou, O.S., Tassou, C., Ersbøll, B.K., Carstensen, J.M., Paganou, E.Z., Nychas, G.J., 2013. Using multispectral imaging for spoilage detection of pork meat. Food Bioprocess Technol. 6 (9), 2268-2279.

Fayyad, U., Piatetsky-Shapiro, G., Smyth, P., 1996. From data mining to knowledge discovery in databases. American Association in Artificial Intelligence 17, 37-54.

Fantazzini, P., Gombia, M., Schembri, P., Simoncini, N., Virgili, R., 2009. Use of magnetic resonance imaging for monitoring Parma dry-cured ham processing. Meat Sci. 82, 219-227.

Garcia, C., Carrapiso, A.I., 2001. La calidad sensorial del jamón Ibérico y su evaluación: La cala y la cata del jamón. In: Ventanas, J. (Ed.), Tecnología del jamón Ibérico. Ed. Mundi Prensa, pp. 391-418. Madrid, Spain.

Harrell Jr., F.E., Lee, K.L., Mark, D.B., 1996. Tutorial in biostatistics. Multivariable prognostic models: issues in developing models, evaluating assumptions and adequacy, and measuring and reducing errors. Stat. Med. 15, 361-387.

Hastie, T., Tibshirani, R., Friedman, J., 2001. In: The Elements of Statistical Learning: Data Mining Inference and Prediction. Springer-Verlag. New York, New York U.S.A.

Hibbert, D.B., 1991. Fractals in chemistry. Chemometr. Intell. Lab. Syst. 11 (1), 1-11.

Hotelling, H., 1936. Relations between two sets of variables. Biometrika 28, $321-377$.

Hyndman, R., Koehler, A.B., 2006. Another look at measures of forecast accuracy. Int. J. Forecast. 22, 679-688.

Hyndman, R., 2006. Another look at forecast accuracy metrics for intermittent demand. International Journal of Applied Forecasting 4, 43-46.

Holmes, G., Fletcher, D., Reutermann, P., 2012. An application of data mining to fruit and vegetable sample identification using gas chromatography-mass spectrometry. In: International Congress on Environmental Modeling and Software Managing Resources of a Limited Planet (Leipzig, Germany).

Kira, K., Rendell, L.A., 1992. A practical approach to feature selection. In: IX International Conference on Machine Learning. Aberdeen, United Kingdom.

Mandelbrot, B.B., 1982. In: Freeman, W.H. (Ed.), The Fractal Geometry of Nature (San Francisco, California, U.S.A).

Manera, M., Giari, L., De Pasquale, J.A., Dezfuli, B.S., 2016. Local connected fractal dimension analysis in gill of fish experimentally exposed to toxicants. Aquat. Toxicol. (Amst.) 175, 12-19.

Manzoco, L., Anese, M., Marzona, S., Innocente, N., Lazagio, C., Nicoli, M.C., 2013. Monitoring dry-curing of San Daniele ham by magnetic resonance imaging. Food Chem. 141, 2246-2252.

Mitchell, T.M., 1999. Machine learning and data mining. Commun. ACM 42, 30-36.

Molano, R., Rodriguez, P.G., Caro, A., Durán, M.L., 2012. Finding the largest area rectangle of arbitrary orientation in a closed contour. Appl. Math. Comput. 218 (19), 9866-9874.

Muriel, E., Ruiz, J., Martin, D., Petrón, M.J., Antequera, T., 2004. Physico-chemical and sensory characteristics of dry-cured loins from different Iberian pig lines. Food Sci. Technol. Int. 10, 117-123.

Packingpaugh, S., 1991. An improved method for computing gray-level co-occurrence matrix based texture measured. Comput. Vis. Graph Image Process 53, $574-580$.

Pérez-Palacios, T., Antequera, T., Durán, M.L., Caro, A., Rodríguez, P.G., Ruiz, J., 2010. MRI-based analysis, lipid composition and sensory traits for studying Iberian dry-cured hams from pigs fed with different diets. Food Res. Int. 43, 248-254.

Pérez-Palacios, T., Antequera, T., Durán, M.L., Caro, A., Rodríguez, P.G., Palacios, R. 2011. MRI-based analysis of feeding background effect on fresh Iberian ham. Food Chem. 126, 1366-1372.
Pérez-Palacios, T., Caballero, D., Caro, A., Rodríguez, P.G., Antequera, T., 2014. Applying data mining and Computer vision techniques to MRI to estimate quality traits in Iberian hams. J. Food Eng. 131, 82-88.

Pérez-Palacios, T., Caballero, D., Caro, A., Antequera, T., 2015. Low-field Magnetic Resonance Imaging and computational texture features to predict moisture and lipid content of loins. In: IV Farm Animal Imaging Conference (Edinburgh, United Kingdom),

Pérez-Palacios, T., Caballero, D., Antequera, T., Durán, M.L., Ávila, M.M., Caro, A., 2017a. Optimization of MRI acquisition and texture analysis to predict physicochemical parameters of loins by data mining. Food Bioprocess Technol. 10, 750-758.

Pérez-Palacios, T., Caballero, D., Caro, A., Antequera, T., 2017b. Algoritmos de fractales para predecir el contenido de grasa y humedad en lomo mediante MRI. In: IX CYTA-CESIA Conference (Madrid, Spain).

Perisho, S.T., Kelty-Stephen, D.G., Hajnal, A., Houser, D., Kuczaj II, S.A., 2016. Fractal scaling in bottlenose dolphin (Tursiops truncates) echolocation: a case study. Physica A 443, 221-230.

Polder, G., Van Der Heijden, G.W.A.M., Van Der Hoet, H., Young, I.T., 2004 Measuring surface distribution of caretones and chlorophyll in ripening tomatoes using imaging spectrometry. Postharvest Biol. Technol. 34, 117-129.

Quevedo, R., Valencia, E., Cuevas, G., Ronceros, B., Pedreschi, F., Bastías, J.M., 2013 Color changes in the Surface of fresh cut meat: a fractal kinetic application. Food Res. Int. 54, 1430-1436.

Quevedo, R., Pedreschi, F., Bastias, J.M., Díaz, O., 2016. Correlation of the fractal enzymatic browning rate with the temperature in mushroom, pear and apple slices. LWT - Food Science and Technology 65, 406-413.

Ruiz, J., Ventanas, J., Cava, R., Timón, M.L., García, C., 1998. Sensory characteristics of Iberian ham: influence of processing time and slice location. Food Res. Int. 31, 53-58.

Ruiz, J., García, C., Muriel, E., Andrés, A.I., Ventanas, J., 2002. Influence of sensory characteristics on the acceptability of dry-cured ham. Meat Sci. 61, 347-354.

Sayad, S., 2011. In: Real Time Data Mining. Self-Help Publishers, Cambridge, Ontario, Canada.

Song, Y.H., Kim, S.J., Lee, S.K., 2002. Evaluation of ultrasound for prediction of carcass meat yield and meat quality in Korean native cattle. Asian J. Anim. Sci. 15 (4), 591-595.

Sun, J., Zhang, Y.B., Dahl, A.B., Conradsen, K., Juul Jensen, D., 2014. Boundary fractal analysis of two cube-oriented grains in partly recrystallized copper. In: XVII International Conference on Texture of Materials. ICOTOM 17. Dresden, Germany).

Tominaga, Y., Fujiwara, L., 1997. Data structure comparison using fractal analysis. Chemometr. Intell. Lab. Syst. 39 (2), 187-193.

Tsuta, M., Sugiyama, J., Sagara, Y., 2002. Near-infrared Imaging Spectroscopy based on sugar absorption band for melons. J. Agric. Food Chem. 50 (1), 48-52.

Witten, I.H., Frank, E., 2005. In: Kaufmann, Morgan (Ed.), Data Mining: Practical Machine Learning Tools and Techniques with Java Implementations (San Francisco, California, U.S.A).

Wu, X., Kumar, V., Ross Quinlan, J., Ghosh, J., Yang, Q., Motoda, H., McLachlan, G.J., Ng, A., Liu, B., Yu, P.S., Zhou, Z.H., Steinbach, M., Hand, D.J., Steinberg, D., 2008. Top 10 algorithms in data mining. Knowl. Inf. Syst. 14, 1-37.

Zapotoczny, P., Szczypinski, P.M., Daszkiewicz, T., 2016. Evaluation of the quality of cold meats by computer-assisted image analysis. LWT - Food Science and Technology 67, 37-49.

Zhang, B., Huang, W., Li, J., Zhao, C., Fan, S., Wu, J., Liu, C., 2014. Principles, developments and applications of computer vision for external quality inspection of fruits and vegetables: a review. Food Res. Int. 62, 326-343. 